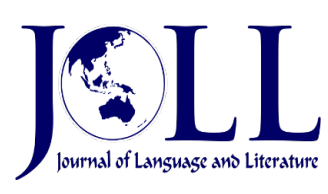

Vol. 21 No. 2, October 2021, pp. 281-293

DOI: 10.24071/joll.v21i2.3056

Available at https://e-journal.usd.ac.id/index.php/JOLL/index

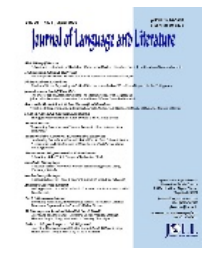

This work is licensed under a Creative Commons Attribution-ShareAlike 4.0 International License.

\title{
Backchannel as a Listener's Consideration Behavior: Politeness Strategy of Japanese Native Speakers in Interaction
}

\author{
Lisda Nurjaleka \\ lisda_nurjaleka@mail.unnes.ac.id \\ Faculty of Language and Arts, Universitas Negeri Semarang, INDONESIA
}

\begin{abstract}
Japanese tend to deliver backchannel for being supportive and representing people's interest in their interaction. Many linguists believed Backchannel as discourse markers that showed interlocutors' negative faces and determined their social hierarchy position. Brown and Levinson's (henceforth B\&L) politeness theory has been modified, criticized, and applied to all languages globally. This research aims to know whether the B\&L politeness theory can explain Backchannel as a consideration behavior. Furthermore, we investigate the position, situation, and the relation between the speaker \& listener in a conversation. The primary data are a data corpus of 30 minutes' length of 15 natural conversations. The age of the target is between the '20s to '40s. We also compare and analyze the situation from a first-timer conversation, a conversation between friends, and a hierarchical relationship. This study will help understand the relation between speaker and listener or whether Backchannel is considered a consideration behavior. Consideration is one act to shows politeness to the interlocutors. The result shows that Japanese people use different Backchannel according to the partner he/she speaks. When the interlocutors meet for the first time or have a higher position, they mostly use the polite form. They also consider the relationship, the interlocutor's gender, and age. This finding shows that the Japanese use Backchannel as a consideration to maintain the interlocutor's face.
\end{abstract}

Keywords: Backchannel; Politeness; Listener response; Consideration behavior

\section{Introduction}

In communication, both interlocutors in the conversation are responsible for smoothing the talk. So, it considers necessary for the listener to react to the partner as it is one of their roles of actively taking part in the conversation. At the conversation level, the partner's consideration action is politeness (Lakoff \& Ide, 2005). In Brown and Levinson's 
(1987, henceforth B\&L) politeness theory, which is widely accepted, a strategy is proposed from the speaker's viewpoint to maintain the partners' face or his. A Backchannel is assumed as one of the listeners' consideration behavior, which differs from the politeness of consideration behavior by a general speaker.

Backchannel or aizuchi in Japanese is a signal showing that a listener is listening to what the speaker says in conversation. Backchannel can be verbal, such as 'uh-huh, or yeah form. 'or non-verbal such as 'nodding' form. According to Cutrone (2011), Backchannel can relate as a polite way for a listener to express that they are paying attention to the conversation. Politeness is one consideration behavior for talking to other people in the conversation (Watts, Ide, Ehlich 2008). A widely known politeness theory (Brown \& Levinson's theory) proposed a strategy from the viewpoint that the speaker maintains the opponent's face. Here, we can understand that politeness is a fundamental listener consideration toward the speaker.

According to Fujimoto (2009), Japanese backchannel or aizuchi is a complex listener behavior and tied to the Japanese communication style and should not be generalized. Another conversation analysis, such as Schegloff (1982), refers to Backchannel as minimal vocalization or general terms as listener response, listener token, or reactive token. However, Japanese Backchannel or aizuchi has more complex work of the listener within conversations.

Because of Japanese backchannel complexity as a listener behavior and its relation with Japanese unique communication style, this study will analyze Japanese backchannel behavior in natural conversation in the formal setting (first-time meeting and status relationship). Moreover, we also analyze informal settings (natural conversation in a friendly relationship) using a Backchannel behavior framework. It assumed that the listener's backchannel in every setting would be different to consider as a politeness strategy.
Backchannel (or in Japanese called aizuchi) is a signal or reaction send from the listener that they understand the speaker's utterance (Maynard 1993, Horiguchi 1997, and others). According to Maynard (1993) and Ike \& Mulder (2015), the Backchannel types classification is as follows.

Table 1. (Maynard, 1993; Ike \& Mulder's Backchannel classification)

\begin{tabular}{|l|l|}
\hline $\begin{array}{l}\text { Verbal } \\
\text { Expression }\end{array}$ & $\begin{array}{l}\text { A short expression like 'un', } \\
\text { 'huun', 'naruhodo','soudesuka' } \\
\text { etc. }\end{array}$ \\
\hline $\begin{array}{l}\text { Non-verbal } \\
\text { expression } \\
\text { (non-vocal) }\end{array}$ & $\begin{array}{l}\text { Head movement } \\
\text { Laughing, expression looks like } \\
\text { laugh }\end{array}$ \\
\hline $\begin{array}{l}\text { Non-verbal } \\
\text { expression } \\
\text { (Display) }\end{array}$ & $\begin{array}{l}\text { Range of volume and voice tempo } \\
\text { (short, gentle) } \\
\text { Speed movement etc. (slow, deep } \\
\text { nod) }\end{array}$ \\
\hline
\end{tabular}

Ide \& Ueno (2012) stated that consideration of language behavior is that the speakers give an appropriate word and show attention to their opponent in the conversation. It is a language behavior to maintain and construct an interpersonal relationship with the opponent. Too considerate means that they preserve the selfesteem of others. In this study, we examine the influence of psychological relationships on Backchannel behavior in a conversation.

In Japanese conversation, the listener responds at the end of the speaker's utterance and contributes in the middle while talking. Moreover, it is called a Backchannel. In communication, speakers and listeners have their responsibility. To smoothing the talk, the listener needs to give a reaction. It is one of the listener's roles as an active participant in the conversation.

From a different perspective, backchannel research is widely analyzed. Others observe the Backchannel relation to politeness and definition of the Backchannel, format, function, and frequency. The relationship between Backchannel frequency and many factors, such as human relationships, subjects, and 
interlocutors' speed in conversation, was not yet considered.

In Tajima's study (2010), Japanese culture is often said to be the listener's culture. Interlocutors must show their propositional content of the utterance. Japanese native speaker also has to show their position and relationship in the conversation. That means that the listener's signal plays an active role in Japanese conversation. By using a Backchannel, Japanese people maintain relationships to create harmony or make psychological distances in the conversation. Therefore, many varieties of backchannel's type seen.

Naito (2003) examined speech levels of aizuchi in the Japanese conversation among Japanese native speakers and advanced Korean learners. She concluded that there was a slight level of speech of aizuchi by the native speakers but not in Japanese learners of Korean. Speech level shift means that the speakers were making adjustments by shifting the speech level; in this case, the Japanese saw to use level speech of aizuchi following the interlocutor's position. This level of a shift of Japanese native speaker's aizuchi occurred at the beginning of the conversation and the last discourse at the end of the conversation.

Many researchers analyzed the function of the Backchannel. Mizutani (1993) stated that the position where Backchannel has appeared is during the speaker's talk, while Maynard (1997) mentions that Backchannel is an utterance that occurs while in the middle of the opponent's right speech. Horiguchi (1997) also pointed out that the listener expresses the same information with the speaker, while the speakers may talk. This Horiguchi's theory was consistent with other researchers. Regarding the Backchannel's timing, Mizutani (2001) pointed out that the listener gives Backchannel. The speaker had a slight break pause in their talk.

Lee (2015) studied speaker-listener differences in age and gender that influenced listeners' linguistic behavior. Results show that female listeners in their twenties mostly use "positive politeness." However, if the interlocutors have different ages and gender, they use formal response expressions. They were furthermore considered negative politeness. This study's results pointed out that there is a different usage of Backchannel expression in the conversation, whether the interlocutors are of the same age or the opponent is older or younger. Not just only by the age difference, in Japanese, difference opponent's gender also influences the type of Backchannel in conversation.

Looking at the previous studies' results, we can see differences in Backchannel usage on conversation flow, the content, and the purpose. The Backchannel that produces in the conversation may differ, considering the opponent's position and the relation between speakers and the listener. Suppose the frequency, the type of Backchannel, and the timing changed according to the social factors, setting, and the speaker's way of speaking. In that case, it leads to how Backchannel contributes to the conversation.

Moreover, in intercultural communication pointed out by Maynard (1997), we can see the difference in each language because of the language culture's different styles. In intercultural communication, we are grasping the difference between the form of each language culture.

The following research questions will be investigated to determine:

(1) Does the backchannel conceptual could be shifting according to the psychological distance of the interlocutors?

(2) And How the gender difference affect the use of backchannel expression?

The hypothesis builds for this study because the shifting of backchannels conceptual such as place of the appearance, backchannel expression of feelings, and backchannel expression in conceptual changes according to the interlocutors' psychological distance. The level shifting for this backchannel conceptual is categorized as one of the listeners showing consideration or politeness to the speakers. 


\section{Methodology}

\section{Research Design}

A natural conversation corpus data was carried out to examine whether, in the Japanese conversation, the native speakers have different use of backchannel towards the interlocutor as responses for consideration behavior. The conversation is approximately 30 minutes' length, a natural conversation. The non-verbal backchannels were excluded from this study. This research design is similar to the design created by Naito (2003), who examined the speech level of aizuchi among Japanese speakers.

In this study, we investigate two different psychological points of view with three settings. The first setting relation is a first-time meeting conversation between the same gender (men and women). We also analyzed a mixed pair, another type of setting is on a friend's relation. A hierarchical relationship such as student and teacher or parents and children end others. We analyzed five pairs of natural conversation data in each setting.

Table 2. (The psychological setting)

\begin{tabular}{|c|c|c|c|c|}
\hline Relation & $\begin{array}{c}\text { Women`s } \\
\text { pair }\end{array}$ & $\begin{array}{c}\text { Men`s } \\
\text { pair }\end{array}$ & $\begin{array}{c}\text { Mix } \\
\text { pair }\end{array}$ & Remarks \\
\hline First-meeting & 3 & 1 & 1 & There`s psychological distance \\
\hline Friends relation & 3 & 1 & 1 & $\begin{array}{c}\text { There is no psychological } \\
\text { distance }\end{array}$ \\
\hline Hierarchical relation & 4 & 1 & & There`s psychological distance \\
\hline
\end{tabular}

\section{Conversation sample setting}

We clarify and analyze the usage changing of backchannel expression, whether there is a different usage in a different psychological distance between interlocutors. - this time, we consider the following hypothesis about a social norm by classifying women group and men`s group.

This study examines Backchannel as a listener's consideration of behavior. This research aims to know whether the B\&L politeness theory can explain Backchannel as a consideration behavior. Furthermore, we investigate the position, situation, and the relation between the speaker and listener in a conversation.

\section{Data Analysis}

In this study, first, we analyze and classify backchannel expression with backchannel timing in conversation. Second, we classify it with a backchannel expression of feelings; the third category is that we investigate backchannel expression as a backchannel conceptual.
1. Backchannel's place of appearance Imaishi (1992) stated backchannel is not always placed anywhere it likes, but it occurs at appropriate timing.

2. Backchannel expression of feelings (sensibility).

Japanese has three primary positive response expressions. Komiya (1986) pointed out that backchannel expression of feelings classified in Japanese, such as 'hai form, ' 'un form, 'ee form.' This expression has an order of respect. For example, 'hai form' is the most respectful expression, 'ee form, ' 'aa form, ' and 'un form' tendency has lower respect orders. When people get friendly, there is a general tendency they use much lower order expressions. These different usages often have one function: to make a formal form or make a polite way of saying the response.

\section{Backchannel expression in conceptual.}

In order to compare and analyze the usage of backchannel expression in conceptual by set the setting. We analyze and divide each expression into backchannel conceptual such as 'soudesuka,' 'soudesu form,' 'sou nandesuka/ sounandesune,' 'sou 
desune/soudesuyone,' 'souka/sokka,' 'sounanya,' ‘sou form. ', 'sounanda,' and others.

\section{Results and Discussion}

Answering the research questions, we proposed and analyzed the Backchannel expression in three Backchannel conceptual frameworks: Backchannel's place of the appearance, backchannel expression of feelings, and backchannel expression in conceptual. To know whether Backchannel is used as a consideration behavior, we examined the speaker and the listener's psychological relationship.

\section{Level shifting in the Backchannels place of appearance depends on who is the interlocutor (psychological distance between interlocutors}

Table 3 to table 6 shows the ratio of backchannel's appearance based on each conversation setting. Table 3 below presents the frequency of backchannel's appearance by Japanese in the first-time meeting.

Table 3. The frequency of backchannel's place of appearance in term of gender (First time meeting setting)

\begin{tabular}{|c|c|c|c|c|}
\hline & $\begin{array}{c}\text { Total of } \\
\text { Utterance }\end{array}$ & $\begin{array}{c}\text { Total of } \\
\text { Backchannel }\end{array}$ & $\begin{array}{c}\text { Backchannel } \\
\text { occurs in the } \\
\text { middle of the } \\
\text { utterance }\end{array}$ & $\begin{array}{c}\text { Backchannel } \\
\text { occurs at the end } \\
\text { of the utterance }\end{array}$ \\
\hline Women & 1513 & $935(61.9 \%)$ & $339(36.2 \%)$ & $597(63.8 \%)$ \\
\hline Men & 524 & $290(55.3 \%)$ & $171(59 \%)$ & $119(41 \%)$ \\
\hline Total & 2037 & $1226(60 \%)$ & $510(41.6 \%)$ & $716(58.4 \%)$ \\
\hline
\end{tabular}

In the first-time meeting, the occurrence of backchannel between men and women is different, according to table 3 . Aside from the total backchannel ratio that has twice much more than men, Japanese women give backchannel above $63 \%$ at the end of the utterance. The Japanese women give "omoiyari" or considerate what the speakers say until the end of the sentence; then, they give a backchannel.

Meanwhile, in the men group, backchannel occurs at the end of the utterance are lower than women. They give backchannel $41 \%$ at the end of the utterance. The findings revealed different frequency usage of men and women in the first-time meeting setting. These results show that Japanese women give much more backchannel than men in the first-time meeting setting. Although, when we use the Ttest to compare, there is no significant difference.

According to Haugh (2005), there is a concept of "place" in Japanese politeness. This result shows that listeners were showing concerns towards the other's place. So, Japanese people acknowledging the place or others. Moreover, in this situation, women tend to use negative politeness by sending signals backchannels at the end of the utterance.

Women tend to use backchannels much more than men in the first meeting, suggesting that women give full consideration to the speaker's talk as a listener. Moreover, according to Kita and Ide (2007), Japanese women speak politely than men. These results also reflect on women's listener response use in the conversation. Whereas, in the setting of friendly relation conversation, we can see that it is a non-hierarchical communication. There is no psychological distance between both of the interlocutors.

Meanwhile, table 4 shows the frequency of backchannel usage in Japanese appearance in the friendly setting. 
Table 4. The frequency of Backchannel's place of appearance in term of gender (Friendly setting)

\begin{tabular}{|l|l|l|l|l|}
\hline & $\begin{array}{c}\text { Total of } \\
\text { Utterance }\end{array}$ & $\begin{array}{c}\text { Total of } \\
\text { Backchannel }\end{array}$ & $\begin{array}{c}\text { Backchannel } \\
\text { occurs in the } \\
\text { middle of the } \\
\text { utterance }\end{array}$ & $\begin{array}{c}\text { Backchannel } \\
\text { occurs at the end } \\
\text { of the utterance }\end{array}$ \\
\hline Women & 1784 & $1347(75 \%)$ & $993(74 \%)$ & $354(27 \%)$ \\
\hline Men & 828 & $310(37 \%)$ & $166(53 \%)$ & $144(47 \%)$ \\
\hline Total & 2612 & $1657(63.4 \%)$ & $1159(69.9 \%)$ & $498(30.1 \%)$ \\
\hline
\end{tabular}

As shown in Table 4 above, Japanese women use a backchannel in the middle of the utterance (74\%). Furthermore, most men are in the same ratio between occurs in the middle of the utterance or the end. Table 4 also describes that the frequency usage of backchannel in the friendly setting between women and men is different. Women have a higher frequency of backchannel in total than men. Here, we can see that Japanese women tend to have higher frequency usage of backchannel than men, whether in the firsttime meeting or friendly setting. Japanese women give backchannel more in the middle of the utterance than at the end of the utterance. It shows that Japanese women tend to give backchannel more in a friendly situation while the speaker talks and is in the middle of the utterance.
In the place of appearance of backchannel in both sets of first-time and friendly settings, Japanese women's backchannel frequency is higher than men's. The results emphasize that Japanese women actively participate in the conversation and highly engage as a listener.

Kogure (2003) revealed that gender differences in the use of backchannels have occurred. Women tend to show a convergence pattern mostly in nonverbal backchannels such as nods. However, these gender differences in the use of backchannels still a context-sensitive matter as the findings amongst studies are different.

Table 5 below presents the frequency of backchannel usage in a hierarchal setting, a conversation between different age speakers, and the relationship between senior and junior at work.

Table 5. The frequency of Backchannel's place of appearance in term of gender (Hierarchal Setting)

\begin{tabular}{|l|l|l|l|l|}
\hline & $\begin{array}{c}\text { Total of } \\
\text { Utterance }\end{array}$ & $\begin{array}{c}\text { Total of } \\
\text { Backchannel }\end{array}$ & $\begin{array}{c}\text { Backchannel occurs in } \\
\text { the middle of the } \\
\text { utterance }\end{array}$ & $\begin{array}{c}\text { Backchannel } \\
\text { occurs in the end } \\
\text { of the utterance }\end{array}$ \\
\hline Women & 2433 & $1877(77 \%)$ & $1329(71 \%)$ & $541(29 \%)$ \\
\hline Men & 603 & $407(68 \%)$ & $235(58 \%)$ & $172(42 \%)$ \\
\hline Total & 3036 & $2284(75 \%)$ & $1564(68.5 \%)$ & $713(31.2 \%)$ \\
\hline
\end{tabular}

Table 5 shows the same result with table 2 , a friendly setting. Women pairs mostly give backchannel in the middle of the utterance for $71 \%$. However, Japanese men give backchannel in the middle of the utterance for $58 \%$ and at the end for $42 \%$. There is a different result between Japanese women and men using a backchannel in the hierarchal setting. These results have the same result as in the friendly setting; women tend to use backchannel more in the middle of the utterance, but not with Japanese men. The ratio between the middle of the utterance and the end of the utterance is the same.

Meanwhile, let us look at the backchannel frequency in total. We can see the difference between a friendly and a hierarchal setting. Japanese women in a friendly setting use much more backchannel $75 \%$ in the conversation 
than men (37\%). However, In the hierarchal setting, both Japanese women and men frequently use a backchannel in the conversation; Japanese women's total frequency is $77 \%$, while men are $68 \%$. The result shows that men tend to use more backchannel if the interlocutor is older or has a higher position than him. We can assume that Japanese men give backchannel as politeness or consideration.

From table 5 above, the listener considers the opponent's position; they give backchannel mainly after the pose between phrase and sentence assumed they gave polite and recognized as one consideration behavior. In the conversation in men pair age around '20s; even though they are in the first-time conversation, they first established their position and the opponent at the beginning of the conversation. The conversation would continue in a friendlier atmosphere if they knew that the opponent's age is the same as theirs. This result also established the usage of the backchannel in the conversation.

Meanwhile, different from the first-meet setting, a backchannel is mainly seen in the middle of the utterance in a friendly setting conversation. Let us look at the active role as a listener in Japanese conversation in a friendly setting. The Japanese tend to use a backchannel in the middle of the utterance while the speakers talk.

Mizutani (1993) classified two Japanese conversation types, (Taiwa or Dialogue) and (kyowa) type. Mizutani stated that Japanese conversations were constructed in cooperation with two participants. "Kyowa" type of conversation means that both speakers have the same understanding without saying, express the opinion or the same feeling, and sympathize with the opponent before even talking. In the friendly setting conversation, if the opponent is someone they knew, the timing of the occurrence and the backchannel place are primarily found in the middle of the utterance.

In the setting of hierarchal relation, in this case, senior and junior relationships, backchannel mostly use in the middle of the utterance. It has the same result as in a friendly setting.
Although the conversation setting is between senior and junior, this somehow stated that there is no psychological distance between senior and junior. However, interlocutors are in a different position or age. The `uchi-soto` Japanese situation can be why the result is the same as a friendly setting. Both interlocutors have the same connection as a group within 'uchi' and no psychological distance.

\section{Backchannel Expression Usage of Feelings}

In Japanese backchannel, native speakers use backchannel expression to express their feeling, such as "un form," "ee form," and "hai form." Here we analyzed these expression usages by comparing women and men in a different setting (first-time meeting, friendly relationship meeting, and hierarchal relationship). These results show that there are different usage by men and women in using these backchannels expression of feeling.

In the Japanese backchannel, there are three primary positive responses in Japanese: 'hai,' 'ee,' and 'un.' Each response is used in various contexts. These different usages often use one of the roles as a formal and polite way to react in the conversation.

According to Angles et al. (2000), A response such as 'Hai' and 'ee' is used to respect and convey expression using the polite form of feedback. On the other hand, a response like 'un` is used for a casual speech style in response to the speaker. On the contrary, response expressions such as hai and 'ee' cannot be used as a simple form of verbal such as 'un` in Japanese conversation. Response expressions like 'hai' and 'ee` were both can be used as a humble form of expression. However, 'ee' is inappropriate to use in a formal situation or when replying to first-time meeting strangers and have a higher social status than the listener.

Komiya also (1986) pointed out that there is a general tendency that backchannel 'hai form, 'ee form, 'a form, ' and 'un form ' have an order of respect. The friendlier the opponent, the usage backchannel is different. According to Komiya, a response expression such as 'hai 
form' and 'e form' has the highest respect order and uses too many older interlocutors. Moreover, if the interlocutor is someone close or has the same age as the speaker, they expect to use a response like 'un form,' 'huum form, 'hee form, and 'hoo form.'
Table 6 below is a backchannel of responsiveness accordingly in respective order.

Table 6. Backchannel expression of responsive divide into a first-meet setting, a friendly relationship setting, and a hierarchal relationship setting

\begin{tabular}{|l|l|l|l|l|}
\hline Setting & 'Un Form` & `Ee Form` & 'Hai Form` & Total \\
\hline First-time meeting & & & & \\
\hline Women & $169(53 \%)$ & $39(12.3 \%)$ & $110(34.6 \%)$ & 318 \\
\hline Men & $64(68 \%)$ & 0 & $30(32 \%)$ & 94 \\
\hline Total & $233(56,5 \%)$ & $39(9,5 \%)$ & $140(34 \%)$ & 412 \\
\hline $\begin{array}{l}\text { Friendly } \\
\text { relationship }\end{array}$ & & & & \\
\hline $\begin{array}{l}\text { Women } \\
\text { Men }\end{array}$ & $233(56,5 \%)$ & $39(9,5 \%)$ & $140(34 \%)$ & 412 \\
\hline Total & $160(81.6 \%)$ & $10(5.1 \%)$ & $12(6.1 \%)$ & 196 \\
\hline $\begin{array}{l}\text { Hierarchal } \\
\text { relationship }\end{array}$ & $1022(87.9 \%)$ & $46(4 \%)$ & $26(2.2 \%)$ & 1194 \\
\hline Women & $62(36.9 \%)$ & $82(48.8 \%)$ & $24(14.3 \%)$ & 168 \\
\hline Men & $1084(81.5 \%)$ & $128(9.6 \%)$ & $119(8.9 \%)$ & 1331 \\
\hline Total & $639(93.8 \%)$ & $19(2.8 \%)$ & $23(3.4 \%)$ & 681 \\
\hline Senior & $445(68.5 \%)$ & $109(16.8 \%)$ & $96(14.8 \%)$ & 650 \\
\hline \begin{tabular}{l} 
Junior \\
\hline
\end{tabular} & & & $95(8.2)$ & 1163 \\
\hline
\end{tabular}

The listener gives many polite forms of backchannel expression to the interlocutor; regardless, there is no relation between the two interlocutors. Table 6 above shows that the frequency of backchannel expression of 'un form `is $56.5 \%$ and followed by `hai form` for $34 \%$. From the emotional communication, 'hai form 'is considered a response expression to gives the interlocutor respect in the formal interaction.

Lee (2015), in her research on listener behavior, stated that there are differences in age or gender. The women listeners at a young age ('20s) somewhat use a more informal expression such as "un" or "sou." This study results show to align with Lee's studies.
Table 6 also reveals that, in a friendly setting, Japanese women and men both use `un form ' expression $90 \%$ above, higher than 'hai form ' and 'ee form' in the conversation. We can assume that 'un form' is considered a casual speech style. Differ from the 'hai form" of backchannel style. In the Japanese backchannel, the use of 'hai' and 'un' response expressions is related to the conversation style, whether we talk politely or not. The backchannel of 'hai' and 'un' can occur and be mixed in one interlocutor's turn.

In the hierarchal relationship setting, the backchannel expression of 'un form ' is high $(81.5 \%)$. This result also has the same result seen in the friendly setting situation. The exciting part is that in the Japanese men's group, the ratio of 'ee form' of listener 
expression is high rather than the other two responses. However, in women`s groups, they tend to use 'un form ' rather than other polite forms of response. However, the interlocutors are in higher positions, such as seniors or older. The speaker acknowledges them as one of their 'uchi' environments, giving the friendlier style of speech or friendlier backchannel.

We concluded that because there is no age difference between interlocutors. Moreover, the conversation is not set as a formal setting. The speakers tend not to use a formal expression. In the conversation, in the hierarchal relationship, both speakers much used more colloquial backchannel expressions.

\section{Backchannel Expression Usage in Conceptual}

We also compared the result of backchannel expression usage in conceptual to know whether there is a different usage in a different setting and compared by gender. Ide (1990) stated that Japanese women tend to speak more politely. Japanese women show negative politeness using higher linguistic forms towards the interlocutor.

Table 7 to 9 below presents the frequency of backchannel expression usage in a conceptual framework based on each setting.

Table 7 Frequency of backchannel expression usage in conceptual (first-time setting situation) (In percentage)

\begin{tabular}{|c|c|c|c|c|c|c|}
\hline Group & \multicolumn{6}{|c|}{ Sou + desu form } \\
\hline & $\begin{array}{c}\text { Sou } \\
\text { desuka }\end{array}$ & $\begin{array}{c}\text { Sou desu } \\
\text { form }\end{array}$ & $\begin{array}{c}\text { Sou } \\
\text { nandesuka/ } \\
\text { sou nan } \\
\text { desune }\end{array}$ & \multicolumn{3}{|c|}{ Sou desune/ sou desuyone } \\
\hline Women & 14.2 & 6.6 & 25.6 & \multicolumn{3}{|l|}{29.8} \\
\hline Men & 8.2 & 0 & 21.3 & \multicolumn{3}{|l|}{44.3} \\
\hline Total & 13.1 & 5.4 & 24.9 & \multicolumn{3}{|l|}{32.3} \\
\hline $\begin{array}{l}\text { Total on each } \\
\text { group }\end{array}$ & 75.7 & & & & & \\
\hline \multirow[t]{2}{*}{ Group } & \multicolumn{6}{|c|}{ Sou + da form } \\
\hline & \multicolumn{2}{|c|}{ Souka/ sokka } & Sounan ya & $\begin{array}{l}\text { Sou } \\
\text { form }\end{array}$ & $\begin{array}{l}\text { Sou } \\
\text { nan da }\end{array}$ & total \\
\hline Women & \multicolumn{2}{|l|}{6.9} & 0.7 & 13.5 & 2.8 & 289 \\
\hline Men & \multicolumn{2}{|l|}{18} & & 1.6 & 6.6 & 61 \\
\hline Total & \multicolumn{2}{|l|}{8.9} & 0.6 & 11.4 & 3.4 & 350 \\
\hline $\begin{array}{l}\text { Total on each } \\
\text { group }\end{array}$ & \multicolumn{2}{|l|}{24.3} & & & & \\
\hline
\end{tabular}

As shown in Table 7 above, Japanese women and men, mostly for $75.5 \%$, are using 'sou+desu form' of backchannel in the conversation in the first-meet setting. They often use 'sou desuka, 'sou nan desuka, ' and 'sou desune/ sou desuyone.' As a whole, these response expressions use the polite form of 'sou+desu+particle ne or yone,' we can see from table 7. The listener mostly used these response expressions toward the interlocutors in the first time setting conversation. We assumed that both Japanese women and men use `sou+ desu form ` to give the interlocutor a polite response expression.

The results show that both Japanese women and men use negative politeness in the first-meet setting. They showed a form of negative politeness by expressing backchannel such as "sou + desu form."

Meanwhile, table 8 below presents backchannel's expression usage in conceptual in a friendly setting conversation. There are three types of conceptual backchannel 
expression in this setting, which are 'sou+da and casual form,' 'others,' and 'sou+desu form.' Besides, in a friendly setting conversation, they use a casual form of 'sou+da form `and a polite form of `sou+desu form'. We found that there is another form such as `final particle+ $\mathrm{Ne}^{\prime}$.

Table 8. Frequency of backchannel expression usage in conceptual (friendly setting situation) (In percentage)

\begin{tabular}{|c|c|c|c|c|c|c|c|c|c|}
\hline \multirow[t]{2}{*}{ Group } & \multicolumn{6}{|c|}{ Sou+ da form/casual form } & \multirow{2}{*}{\begin{tabular}{|l|} 
Others \\
Final \\
particle+ \\
ne
\end{tabular}} & \multirow{2}{*}{\begin{tabular}{|l|} 
Sou + desu \\
form \\
sou \\
desune/ \\
sou desu
\end{tabular}} & \multirow[t]{2}{*}{ Total } \\
\hline & $\begin{array}{l}\text { Sou } \\
\text { dane/ } \\
\text { souda }\end{array}$ & $\begin{array}{l}\text { Sou } \\
\text { nanda/ } \\
\text { sounan } \\
\text { dayone }\end{array}$ & $\begin{array}{l}\text { Soudayone/ } \\
\text { soudayo }\end{array}$ & $\begin{array}{l}\text { Sounano/ } \\
\text { souyana }\end{array}$ & $\begin{array}{l}\text { Sou } \\
\text { form }\end{array}$ & $\begin{array}{l}\text { Soukka/ } \\
\text { sokka }\end{array}$ & & & \\
\hline Women & 15.8 & 21.5 & 12.7 & 2.5 & 34.8 & 12 & 0.6 & 0 & 158 \\
\hline Men & 3.2 & 1.6 & 6.3 & 7.9 & 31.7 & 23.8 & 1.6 & 23.8 & 63 \\
\hline Total & 12.2 & 15.8 & 10.9 & 4 & 33.9 & 15.4 & 0.9 & 6.8 & 221 \\
\hline $\begin{array}{l}\text { Total on } \\
\text { each group }\end{array}$ & 92.2 & & & & & & 0.9 & 6.8 & \\
\hline
\end{tabular}

The result from table 8 differs from the result from table 7. Japanese people use different backchannel expression forms to the interlocutors. If the person they are speaking to is friends, they use casual backchannel expression. Such as "sou dane", or " souka/sokka".

As shown in Table 8 above, in a friendly setting conversation, as we can see, the ratio of casual form backchannel expression of 'sou+da form' is $92.2 \%$, much more than 'final particle+ne` form and 'sou+desu form.' In this result, there are different usage of backchannel expression by Japanese women and men in conceptual. However, both women and men mostly use a casual form such as 'sou dane, 'sou dayone, 'sou nanda,' and others. There are no differences in using backchannel expression in a casual form in friendly Japanese women and men.

These results confirm Cutrone's (2011) theory on the use of face theory when using backchannels. According to Cutrone (2011), Japanese speakers use negative faces to their interlocutors when using backchannels.

Meanwhile, table 9 shows the frequency of Backchannel expression usage in conceptual in a hierarchal relationship.

Table 9 Frequency of Backchannel expression usage in conceptual (hierarchal relationship setting)

\begin{tabular}{|c|c|c|c|c|}
\hline Group & \multicolumn{4}{|c|}{ Sou+ desu form } \\
\hline & $\begin{array}{c}\text { Sou } \\
\text { desune/sou } \\
\text { desuyone }\end{array}$ & Sou desuka & $\begin{array}{c}\text { Sou } \\
\text { nandesuka/ } \\
\text { sou } \\
\text { nandesuyo }\end{array}$ & soudesu \\
\hline Women & 9.8 & 4.4 & 5.3 & 1.3 \\
\hline Men & 19.5 & 2.4 & 4.9 & 2.4 \\
\hline Total & 12.4 & 3.9 & 5.2 & 1.6 \\
\hline $\begin{array}{c}\text { Total on each } \\
\text { group }\end{array}$ & 23.1 & & & \\
\hline Group & \multicolumn{3}{|c|}{ Sou+da/casual form } & Others \\
\hline
\end{tabular}




\begin{tabular}{|c|c|c|c|c|c|}
\hline & Sou form & $\begin{array}{c}\text { Sou } \\
\text { dane/ } \\
\text { sou } \\
\text { dayone }\end{array}$ & $\begin{array}{c}\text { Sou } \\
\text { nanda/ } \\
\text { sou dayo }\end{array}$ & $\begin{array}{c}\text { Souka/ } \\
\text { sokka }\end{array}$ & $\begin{array}{c}\text { Final particle+ } \\
\text { Ne }\end{array}$ \\
\hline Women & 40 & 6.7 & 2.7 & 25.3 & 4.4 \\
\hline Men & 8.5 & 22 & 6.1 & 34.1 & 3.3 \\
\hline Total & 31.6 & 10.7 & 3.6 & 27.7 & 3.3 \\
\hline $\begin{array}{c}\text { Total in each } \\
\text { group }\end{array}$ & \multicolumn{7}{|c|}{73.6} & \\
\hline
\end{tabular}

Table 7 reveals that both Japanese women and men use a casual form of backchannel expression in conceptual for $73.6 \%$ in a conversation. Japanese women use `sou form` for $40 \%$ meanwhile Japanese men only $8.5 \%$. Japanese women and men both use the backchannel expression of "souka/sokka" in this hierarchal relationship situation.

From the above results, we conclude that Japanese women and men both use formal and casual speech in this setting. Formal and casual backchannel forms occurred because we collected a slight age difference in the corpus data we collected. So, they still use both casual and formal backchannel forms.

\section{Conclusion}

In conclusion from the above result and discussion are described in tables. We conclude that Japanese native speakers use different backchannels expression in a different setting. We know from the result that formal and informal situations or psychological factors between interlocutors can affect backchannels. Japanese native speakers considered first-time meeting setting as a formal situation, so they send formal backchannels.

In some studies, there is evidence that backchannel considered use as politeness. Moreover, Japanese native speakers frequently sent backchannels to signal support or empathy towards the speaker, as is customary in Japanese culture. (Cutrone, 2011). This action of giving backchannels by the listener is to build a harmonious atmosphere in the conversation. These backchannel behavior usage could affect the negative face of their interlocutors.
This study showed that Japanese native speakers, both men, and women use different backchannels. We also analyzed that there are different placement of backchannels. Furthermore, when there is a psychological distance between interlocutors, the placement of backchannels also differs.

In Japanese conversation, a distinction in the use of backchannel expression expresses consideration for the interlocutors. Thus, backchannel can be considered a consideration of the listener's behavior in Japanese. So, listeners refrain from giving the FTA (face-threatening Act). This result is consistent with the outcome of Horiguchi (1997). In his study, Horiguchi (1997) reports different factors that influence the backchannel expression. A listener provides a Backchannel through the flow of conversation, content, and purpose. Japanese native speakers also consider the connection, which is gender and age.

These results also support Tajima's (2001) study that Japanese people broadly use backchannel by hierarchical factors such as age, gender, and interlocutors' status. In Tajima's study, he found that the conversation setting's formality may affect different backchannel expressions. Furthermore, Japanese native speakers as a listener also use a backchannel to mitigate FTAs by shifting the style of their backchannel forms.

However, we could not support further data in the hierarchical setting. The collected data are limited in age differences and junior and senior relationships within the company only. Moreover, the results show that there is no much more age difference in the conversation. Japanese native speakers are 
considered in the "uchi" group, so the listeners use informal forms such as un, aa, and sou.

This study's implication for intercultural communication and second language pedagogy is essential. We need to look closely at backchannel behavior changes according to the interlocutor's background much further.

\section{References}

Angles, J., Nagatomi, A., \& Nakayama, M. (2000). Japanese responses hai, ee, and un: yes, no, and beyond. Language \& Communication, 20(1), 55-86. https://eric.ed.gov/?id=EJ595071

Brown, P., Levinson, S. (1987). Politeness: Some Universals in Language Usage. Cambridge University Press.

Cutrone, Pino. (2011). Politeness and Face Theory: Implications for the Backchannel Style of Japanese L1/L2 Speakers. Language Studies Working Papers, 3, 5157. Retrieved from https://www.reading.ac.uk/web/files/en glish-language-andliterature/ell_language_6_Cutrone_vol_3. pdf

Fujimoto, D. T. (2009). Listener responses in interaction: A case for abandoning the term, backchannel. Bulletin paper of Osaka Jogakuin College, 37, 35-54.

Retrieved from

http://irlib.wilmina.ac.jp/dspace/bitstrea $\underline{m} / 10775 / 48 / 1 / 03 . p d f$

Haugh, M. (2005). The importance of "place" in Japanese politeness: Implications for cross-cultural and intercultural analyses. Intercultural Pragmatics, 2(1), 41-68. https://doi.org/10.1515/iprg.2005.2.1.4 1

Horiguchi, Junko. (1997). Nihongo kyouiku to Kaiwa Bunseki. Tokyo: Kuroshio Publisher.

Ide, S. (1990). How and why do women speak more politely in Japanese. Aspects of
Japanese women's language, 63-79. Retrieved from http://www.sachikoide.com/1991b_How _and_Why_Do_Women_Speak.pdf

Ide, Sachiko, \& Ueno, Kishiko. (2012). Ba no riron de kangaeru hairyou koudou 'Hairyou koudou' wa dono youni shimesareruka. Tokyo: Hitsuji Shobo Publisher.

Imaishi, Sachiko. (1992). Danwa ni okeru kikite no koudou - aizuchi no taimingu nit suite--. Nihongo Kyouiku Gakkai Souritsu 30-Shuunen Houjin Setsuritsu 15 Shuunenkinen Taikai Yoko-shu, 147-151.

Kita, S., \& Ide, S. (2007). Nodding, aizuchi, and final particles in Japanese conversation: How conversation reflects the ideology of communication and social relationships. Journal of Pragmatics, 39(7), 1242-1254. https://doi.org/10.1016/j.pragma.2007. $\underline{02.009}$

Kogure, M. (2003). Gender differences in the use of backchannels: Do Japanese men and women accommodate to each other? University of Arizona.

Komiya, Chizuru. (1986). Aizuchi Shiyou no Jittai - Shutsugen Keikou to Sono Shuuhen--. Gogaku Kyouiku Kenkyuu Ronsou Vol. 3, Daitou Bunka Daigaku Gogaku Kyouiku Kenkyuusho, 43-62.

Lakoff, R. T., \& Ide, S. (Eds.). (2005). Broadening the horizon of linguistic politeness (Vol. 139). John Benjamins Publishing.

Lee, Soonhyung. (2015). Taiwa aite to no nen rei sa/ seisa ni oujita kikite gengo koudou no shiyou jittai. Journal of Nihongakubou, 105 (11), 147-164. Retrieved from https://www.earticle.net/Article/A3155 70

Maynard, Senko, K. (1993). Kaiwa Bunseki. Tokyo: Kuroshio Publisher.

Maynard, S. K. (1997). Analyzing interactional management in native/non-native English conversation: A case of listener response. IRAL, International Review of Applied Linguistics in Language Teaching, 35(1), 37. Retrieved from https://search.proquest.com/openview/ d82daf4e37ab4a3a3cf872afdba0eb11/1? pq-origsite $=$ gscholar $\& \mathrm{cbl}=47386$ 
Mizutani, Nobuko (1993). 'Kyouwa' kara 'Taiwa` e. Journal of Nihongogaku, 12-4, Meiji Shoten, 4-10.

Mizutani, Nobuko. (2001). Aizuchi to po-zu ni shinrigaku [Psychology of aizuchi and pause]. Gengo, pp. 46-51. Retrieved from https://ci.nii.ac.jp/naid/40001056328

Naito, M. (2003). Speech levels of aizuchi and their shifts: Differences between native Japanese and Korean learners of Japanese. Japanese-Language Education Around the Globe 13, 109-125. Retrieved from https://ci.nii.ac.jp/naid/110000941387

Saya, Ike. \& Jean, Mulder (2015). Conceptualising Backchanel Behaviour in Japanese English and Australian English. Proceeding in $18^{\text {th }}$ Annual Conference of the Pragmatics society of Japan, The Pragmatics Society of Japan, 191-198. Retrieved from https://minervaaccess.unimelb.edu.au/handle/11343/12 7213

Schegloff, E. A. (1982). Discourse as an interactional achievement: Some uses of 'uh-huh' and other things that come between sentences. Analyzing discourse: Text and talk, 71, 93. Retrieved from https://repository.library.georgetown.ed $\mathrm{u} /$ bitstream/handle/10822/555474/GU RT_1981.pdf\#page $=87$

Tajima, K. (2001). Pragmatic use of aizuchi in Japanese discourse: A comparison with English backchannels. The Academic Reports, the Faculty of Engineering, Tokyo Polytechnic University, 24(2), 54-60. Retrieve from https://core.ac.uk/reader/234015820

Tajima, Kaori. (2010). Pragmatic Use of Aizuchi in Japanese Discourse: A Comparison with English Backchannels. Academic Report Fac. Eng. Tokyo Inst. Polytech. Vol. 24 (2), 54-60. Retrieved from

https://core.ac.uk/reader/234015820

Watts, R. J., Ide, S., \& Ehlich, K. (Eds.). (2008). Politeness in language: Studies in its history, theory and practice. Walter de Gruyter. 